\title{
Phylogenetic relationships of Iranian Allium species using the matK (cpDNA gene) region
}

\author{
Hemadollah Zarei • Barat Ali Fakheri - Mohammad Reza Naghavi • Nafiseh Mahdinezhad
}

Received: 6 December 2019 / Revised: 25 December 2019 / Accepted: 27 January 2020

(C) Korean Society for Plant Biotechnology

\begin{abstract}
Allium L. is one of the largest genera of the Amaryllidaceae family, with more than 920 species including many economically important species used as vegetables, spices, medicines, or ornamental plants. Currently, DNA barcoding tools are being successfully used for the molecular taxonomy of Allium. A total of 46 Allium species were collected from their native areas, and DNA was extracted using the IBRC DNA extraction kit. We used specific primers to PCR amplify matK. DNA sequences were edited and aligned for homology, and a phylogenetic tree was constructed using the neighbor-joining method. The results show thymine (38.5\%) was the most frequent and guanine (13.9\%) the least frequent nucleotide. The matK regions of the populations were quite highly conserved, and the amount of $\mathrm{C}$ and CT was calculated at 0.162 and 0.26 , respectively. Analysis of the nucleotide substitution showed C-T (26.22\%) and A-G $(8.08 \%)$ to have the highest and lowest percent, respectively. The natural selection process $\mathrm{dN} / \mathrm{dS}$ was 1.16 , and the naturality test results were -1.5 for Tajima's D and -1.19 for Fu's Fs. The NJ dendrogram generated three distinct clades: the first contained Allium austroiranicum and $A$. ampeloprasum; the second contained $A$. iranshahrii, A. bisotunense, and A. cf assadi; and the third contained $A$. rubellum and other species. In this study, we tested the utility of the $m a t K$ region as a DNA barcode for discriminating
\end{abstract}

H. Zarei $(\bowtie) \cdot$ B. A. Fakheri $\cdot$ N. Mahdinezhad Department of Plant Breeding and Biotechnology, Faculty of Agriculture, University of Zabol, Zabol, Iran e-mail: h.zarei1989@gmail.com

M. R. Naghavi

Department of Agronomy and Plant Breeding, College of Agriculture and Natural Resources, University of Tehran, Karaj, Iran

H. Zarei · M. R. Naghavi

Plant Bank, Iranian Biological Resource Center (IBRC),

ACECR, Tehran, Iran
Allium. species.

Keywords cpDNA, marker, Molecular phylogeny, matK, Allium, Taxa

\section{Introduction}

Allium L. falls under one of the widespread and main genera in the Amaryllidaceae family (Friesen et al. 2006; Li et al. 2010; Fritsch et al. 2010). As of Linnaeus, the number of species have risen from 30 to over 920 species at present (Govaerts et al. 2005-2014). There are some species of economic importance in the genus, namely onion, garlic, leek, shallot, bunching onion, and chives planted as vegetables or spices, as well as species utilized as seasoning crops, traditionally used medications, and ornamental plants (Fritsch and Friesen, 2002).

The main focus of investigators has been on existing natural plants that are recently cultivated in investigations, and most of Allium newly introduced species have been found in Iran. A number of recent species and subspecies achieved scientific qualification from some regions in Iran (Akhani 1999; Fritsch et al. 2001; Fritsch et al. 2002; Fritsch et al. 2006; Fritsch and Abbasi 2008; Fritsch and Maroofi 2010; Kamelin and Seisums 1996; Khassanov and Memariani 2006; Khassanov et al. 2006; Mashayekhi et al. 2005; Memariani et al. 2007; Neshati et al. 2009; Razyfard et al. 2011). A comparison was made among 170 species and subspecies, and their diverse types in Southwest Asia, mainly in Iran and Turkey, with over 120 species identified in Iran classified into seven subgenera and 30 sections (Friesen et al. 2006; Fritsch and Maroofi 2010; Fritsch and Abbasi 2013; Memariani et al. 2012). Allium genus is generic for the IranoTuranian Phyto-geographic zone and represents a highly endemic rate (Matin 1992).

To increase the number of qualitative traits for tightly 
related species, molecular markers have greater capability than morphologic characters, most of which present only quantitatively diverse attributes (Harpke et al. 2013). Linne von Berg pioneered in a publication for the organization of the Allium genus by molecular markers (von Berg et al. 1996). Friesen then innovated the classification of Allium in publication according to molecular techniques (Friesen et al. 2006). Thereafter, Allium was affirmed monophyletically by the entire scientific reports (Choi et al. 2012; Li et al. 2010; Nguyen et al. 2008). Despite a huge body of research, perfect studies have not been conducted on the whole subgenera regarding the phylogenetic condition of their species (Friesen et al. 2006).

Currently, the DNA barcoding technique has been proven as an instructive and efficacious procedure for assessing plant phylogenies and presented successful applications in the molecular classification of Allium (Abdulina, 1999; von Berg et al. 1996). The basis of barcoding technique is on the alignment of short sequences of DNA markers of the nuclear and plastid genomes (Kress, 2017; Li et al. 2015). The analysis of phylogenetic associations and plant identification surveys have initially used variabilities of the nucleotide sequence in plastid DNA (cpDNA) at inter-specific (among family or genus) and intra-specific levels (into the species or varieties) (Tamura et al. 2004).

The $m a t K$ is a chloroplast gene that encodes a locus in the intron of the trnk gene region. The gene encodes a maturase on the large single-copy part at the adjacency of the inverted repeat of plant species. The matk has vast substitution rates in comparison to other chloroplast genes, and its gene sequence lies among the lowest conserved plastid genes; hence, it has received effective uses in plant evolution and solving phylogenetic equations in a variety of taxonomic levels (Fuse and Tamura, 2000; Ito et al. 1999).

$m a t K$ gene is very beneficial over other genes that contain the organelle genome genes. Firstly, this gene undergoes evolution nearly thrice as fast as the vastly applied plastid genes such as $r b c L$ and $a t p B$. matk gene is in the chloroplast genome and, in general, it has maternal inheritance. The gene is sensibly sizeable, with an extensive substitution rate, a large ratio of alterations at the first and the second codon positions, a low transition/transversion ratio, and the occurrence of mutationally conserved segments. It is also powerful and efficacious in species discrimination, and has excellent sequence recovery rate, a simple technique experimentally, a facile sequence alignment, and nonexistence of allelic polymorphisms or manifold paralogous copies against the nuclear DNA genome. It was demonstrated that the conversion at nucleic acid (DNA) and amino acid levels have even distri- bution throughout the whole gene. Apparently, the 5' region of the $m a t K$ gene contains a greater variation than the 3 ' region in some monocotyledons and dicotyledons. To address family and even species-level associations, mat $K$ gene sequences (at both nucleic acids and amino acid sequence levels) has had successful applications for these specific attributes (Brochmann et al. 1998; Burgess et al. 2011; Hollingsworth et al. 2009; Koch et al. 2001; Lahaye et al. 2008; Steele and Vigalys, 1994; Tamura et al. 2004). To distinguish numerous plant species, the matK DNA gene has been utilized as a barcode gene alone or combined with other plant barcode sequences in current investigations (Bandara et al. 2013; De Mattia et al. 2011; Guo et al. 2011; Jing et al. 2011; Lahaye et al. 2008; Li et al. 2011; Pang et al. 2011; Seberg et al. 2012; Zhi-Yuan et al. 2011).

\section{Material and Method}

Plant materials

Totally, 46 species in 11 sections representative of five subgenera of Allium were gathered from their natural habitat and relocated to the Iranian Biological Resource Center (IBRC), located in Karaj province of Iran during 2017-2018 (Table 1). The identification of the specimens was according to morphologic traits and diagnostic explanations of the species in related publications (Fritsch and Abbasi, 2013; Wendelbo, 1971). The genus was classified according to up-to-date infrageneric concepts presented previously (Friesen et al. 2006, Fritsch et al. 2010, and Fritsch and Abbasi 2013).

DNA extraction, PCR Amplification and DNA Sequencing

The entire DNA was extracted from fresh leaf tissues of Allium species by the "IBRC plant extraction kit" (IBRC IND.) as recommended by the manufacturer's protocol. The extracted DNA was assessed spectrophotometrically in terms of concentration and quality by determination of the absorbance at $260 \mathrm{~nm}$ and $280 \mathrm{~nm}$. Different concentrations of template DNA and $\mathrm{Mg}$ and different annealing temperatures were used to optimize the PCR condition. Next, the PCR reaction materials were set in a final volume of $50 \mu \mathrm{L}$ using Taq DNA Polymerase Master Mix RED (Amplicon), $1 \mathrm{ng}$ of the primers, and $0.5 \mu \mathrm{L}$ of genomic DNA.

The matK region was amplified using the primers 5'CGA TCT ATT CAT TCA ATA TTT C- 3' and 5'- TCT AGC ACA CGA AAG TCG AAG T -3', matK 390F and 
Table 1 Allium species analyzed using nucleotide sequences of matK DNA regions

\begin{tabular}{|c|c|c|c|c|}
\hline Code & Species & Subgenus & Section & Accession number \\
\hline 1 & A. akaka sub akaka & Melanocrommyum & Acanthoprason & P1009858 \\
\hline 2 & A. akaka sub bozghushense & Melanocrommyum & Acanthoprason & P1011312 \\
\hline 3 & A. alamutense & Melanocrommyum & Acanthoprason & P1010457 \\
\hline 4 & A. ampeloprasum sub ampeloprasum & Allium & Allium & P1010913 \\
\hline 5 & A. ampeloprasum sub porrum & Allium & Allium & P1010908 \\
\hline 6 & A. asarence & Cepa & Cepa & P1004474 \\
\hline 7 & A. atroviolaceum & Allium & Allium & P1006775 \\
\hline 8 & A. austroiranicum & Melanocrommyum & Acanthoprason & P1009666 \\
\hline 9 & A. bisotunense & Melanocrommyum & Melanocrommyum & P1011153 \\
\hline 10 & A. breviscapum & Melanocrommyum & Acanthoprason & P1010598 \\
\hline 11 & A. breviscapum & Melanocrommyum & Acanthoprason & P1010598 \\
\hline 12 & A. сера & Cepa & Cepa & P1010909 \\
\hline 13 & A. cf. assadi & Melanocrommyum & Megaloprason & P1011015 \\
\hline 14 & A. cf. cardiostemon & Melanocrommyum & Melanocrommyum & P1009998 \\
\hline 15 & A. cf. latifolium & Melanocrommyum & Acanthoprason & P1010022 \\
\hline 16 & A. chrysantherum & Melanocrommyum & Melanocrommyum & P1010382 \\
\hline 17 & A. derderianum & Melanocrommyum & Acanthoprason & P1009475 \\
\hline 18 & A. egorovae & Melanocrommyum & Acanthoprason & P1011306 \\
\hline 19 & A. fistulosum & Cepa & Cepa & P1010910 \\
\hline 20 & A. haemanthoides & Melanocrommyum & Acanthoprason & P1011119 \\
\hline 21 & A. iranicum & Allium & Allium & P1009733 \\
\hline 22 & A. iranshahrii & Melanocrommyum & Acanthoprason & P1011271 \\
\hline 23 & A. kazerouni & Melanocrommyum & Procerallium & P1010341 \\
\hline 24 & A. keusgenii & Melanocrommyum & Melanocrommyum & P1010423 \\
\hline 25 & A. koelzii & Melanocrommyum & Pseudoprason & P1010355 \\
\hline 26 & A. latifolium & Melanocrommyum & Acanthoprason & P1011289 \\
\hline 27 & A. mahneshanense & Melanocrommyum & Acanthoprason & P1010524 \\
\hline 28 & A. materculae & Melanocrommyum & Acanthoprason & P1009955 \\
\hline 29 & A. cf. minutiflorum & Melanocrommyum & Acanthoprason & P1010986 \\
\hline 30 & A. moderense & Melanocrommyum & Melanocrommyum & P1011021 \\
\hline 31 & A. mozaffarianii & Melanocrommyum & Melanocrommyum & P1011232 \\
\hline 32 & A. pesodoholandicum & Melanocrommyum & Procerallium & P1010545 \\
\hline 33 & A. psedoampeloprasum & Allium & Allium & P1009877 \\
\hline 34 & A. rubellum & Allium & Avulsea & P1009972 \\
\hline 35 & A. sabalanense & Melanocrommyum & Acanthoprason & P1009837 \\
\hline 36 & A. sativum & Allium & Allium & P1010653 \\
\hline 37 & A. scabriscapum & Reticulatobulbosa & Scabriscapa & P1009668 \\
\hline 38 & A. scabriscapum & Reticulatobulbosa & Scabriscapa & P1009668 \\
\hline 39 & A. stamineum & Allium & Codonoprasum & P1009964 \\
\hline 40 & A. stipitatum & Melanocrommyum & Procerallium & P1010429 \\
\hline 41 & A. sub akaka & Melanocrommyum & Acanthoprason & P1009965 \\
\hline 42 & A. tripedale & Nectaroscordum & Nectaroscordum & P1009676 \\
\hline 43 & A. ubipetrense & Melanocrommyum & Acanthoprason & P1010544 \\
\hline 44 & A. umbilicatum & Allium & Avulsea & P1009439 \\
\hline 45 & A. zagricum & Melanocrommyum & Acanthoprason & P1011079 \\
\hline 46 & Allium Sp. & Melanocrommyum & Acanthoprason & P1009928 \\
\hline
\end{tabular}

$m a t K 1326 \mathrm{R}$ primers for matK gene. DNA was amplified on an Eppendorf Master cycler gradient (Eppendorf Scientific, Germany) with the setting below: initial denaturation for $2 \mathrm{~min}$ at $92^{\circ} \mathrm{C}$, followed by 35 cycles of denaturation $\left(94^{\circ} \mathrm{C}\right.$, $1 \mathrm{~min})$, annealing $\left(55^{\circ} \mathrm{C}, 1 \mathrm{~min}\right)$, extension $\left(72^{\circ} \mathrm{C}, 55 \mathrm{sec}\right)$; and a final extension for $5 \mathrm{~min}$ at $72^{\circ} \mathrm{C}$. After completion of the PCR reaction, $5 \mu$ of PCR solution with $5 \mu \mathrm{L}$ loading buffer was decanted into $1.5 \%$ agarose gel well holding TBE buffer. The PCR products were subjected to electrophoresis at $90 \mathrm{~V}$ for $85 \mathrm{~min}$. Thereafter, the agarose gel was stained for $20 \mathrm{~min}$ in $0.50 \mathrm{mg} / 1$ of ethidium bromide and replicated fragments were visualized under UV light 


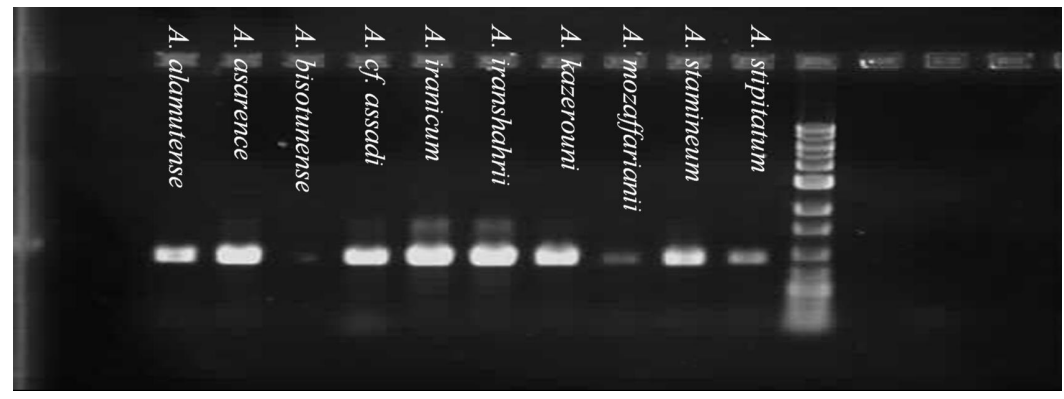

Fig. 1 Electrophoresis of purified PCR products of matK gene from Allium species

followed by gel document imaging. These PCR products were purified by the IBRC DNA purification kit (IBRC, Iran) based on the manufacturer's instructions. A $10 \mathrm{kbp}$ DNA ladder (Thermo Scientific, USA) was utilized as a molecular size standard (Fig. 1). PCR amplification was redone two times or sometimes more for each primer to ensure that the results were reproducible. The sequencing products were produced with the Sanger method by MWG Co. (Germany) that performed sequencing in both directions by the PCR primers.

Editing, Sequence Alignment and Phylogenetic Reconstruction

Extraction of DNA sequences was performed from the chromatograms of the company by the use of Chromas v2, which were edited by the BioEdit program (Hall et al. 1999). The sequences were then put together with the CAP3 tool (Huang et al. 1999) and alignment of the homologous sequences was carried out using the EMBL-EBI CLUSTAL W tool (Edgar, 2004). The MEGA v6.0 software was used to analyze the multiple sequence alignment (MSA) file (Tamura et al. 2011). The genetic distance per loci among the accessions was estimated based on the number of base-pair replacement among the sequences. All the positions with missing data were eliminated by Kimura's 2-parameter model. Moreover, the distance between matrices from the three loci by DNAsp was analyzed with Pearson's correlation. The phylogenetic tree was developed by the Maximum Parsimony (MP) and Neighbor Joining (NJ) approach with a 1000 replicate bootstrap by the MEGA 6.0 software.

For estimating the resolution of DNA barcode, the percentage of produced monophyletic groups was determined using a bootstrap greater than $50 \%$ as a factor for defining the nodes, as recommended by Tripathi in DNAsp (Tripathi et al. 2013). The Tajima's D and Fu's Fs naturality tests were calculated by the DNAsp software. The amount of the $\mathrm{dN} / \mathrm{dS}$ ratio was obtained numerically by the use of HIV databases. Haplotype network was scrutinized by the popART software (Leigh and Beryant, 2015).

\section{Results}

The scientific progressive innovations in molecular science and sequencing approaches has empowered the recognition of organismal genomes. Besides, important data are provided by continuing variety of ongoing genome projects for multiple species concerning their classification, gene structure, and application scientifically. Here, nucleotide polymorphisms of the matK gene quality are applied for 46 species of Allium to recognize the levels and patterns of interspecific and distinctions.

According to our findings on the analyzed matK gene sequence in Allium species, thymine (38.5\%) and guanine $(13.9 \%)$ bases had the most remarkable and the lowest nucleotide rates (Table 2). In the nucleotide substitution recorded in the Allium species, substitution rates were detected significantly in pyrimidine, namely 26.22 for C-T and $10.68 \%$ for T-C conversions (Table 3 ). The above levels were less for purines for the G-A and A-G conversions (19.22\% and 8.08\%, respectively). These findings correspond to those of other investigators reporting consecutive cases of pyrimidine substitutions, which most probably result from cytosine methylation (Picoult et al. 1999).

A total of 595 mutations was identified for genetic indicators of the matK gene in Allium species, which had different distributions all over the genome. Polymorphisms were detected in 243 sites, demonstrating the process of

Table 2 Nucleotide abundances derived from the matK gene of Allium species

\begin{tabular}{ccccc}
\hline $\mathrm{G}$ & $\mathrm{C}$ & $\mathrm{T} / \mathrm{U}$ & $\mathrm{A}$ & Nucleotide \\
\hline 13.9 & 15.2 & 38.5 & 32.4 & Frequency \\
\hline
\end{tabular}


Table 3 Nucleotide substitution pattern estimation matrix of the matK gene in Allium species

\begin{tabular}{ccccc}
\hline$G$ & $\mathrm{C}$ & $\mathrm{T}$ & $\mathrm{A}$ & $\mathrm{F}$ \\
\hline $\mathbf{8 . 0 8}$ & 2.75 & 6.74 & 5.92 & $\mathrm{~A}$ \\
2.49 & $\mathbf{1 0 . 6 8}$ & - & 5.92 & $\mathrm{~T}$ \\
8.49 & - & $\mathbf{2 6 . 2 2}$ & $\mathbf{1 9 . 2 2}$ & $\mathrm{C}$ \\
- & 2.75 & 6.74 & $\mathrm{G}$ \\
\hline
\end{tabular}

Each value represents the frequency of substitutions from one base (row) to another base (column). In this table, the percentage of transition mutations (purine-purine substitution, pyrimidine-pyrimidine substitution) and transversion mutations (purine-pyrimidine substitution and vice versa) are shown in bold and italics, respectively.

Table 4 Gene polymorphism of matK location in Allium species

\begin{tabular}{ccccccc}
\hline $\mathrm{K}$ & Eta & Pi & Hd & H & S & Population \\
\hline 80.112 & 595 & 0.160 & 0.9874 & 39 & 423 & Allium \\
\hline
\end{tabular}

S: Number of polymorphic positions, H: number of haplotypes, Pi: nucleotide diversity, Eta: total number of mutations, K: number of nucleotide differences between populations or species (nucleotide divergence)

Table 5 Conserved DNA regions of the matK gene in Allium species

\begin{tabular}{cccc}
\hline CT & MWL & C & Population \\
\hline 0.26 & 50 & 0.162 & Allium \\
\hline
\end{tabular}

C: Sequence conservation, MWL: Minimum conservation Length, CT: Conservation threshold

Table 6 Identification of the $m a t K$ gene natural selection process in Allium species

\begin{tabular}{cc}
\hline Numerical value & Parameter \\
\hline 2.3254 & $\mathrm{dN}$ \\
1.9970 & $\mathrm{dS}$ \\
1.1644 & $\mathrm{dN} / \mathrm{dS}^{\dagger}$ \\
\hline
\end{tabular}

${ }^{\dagger}$ The numerical value of $\mathrm{dn} / \mathrm{ds}$ represents the natural selection process

a positive selection of the mat $K$ gene sequence (Table 4). Searching for conserved DNA sections of the matK gene in the Allium species revealed a $0.26 \mathrm{CT}$ region, a MWL of 50 bases, and a sequence conservation of 0.162 (Table 5). These conserved sections comprised a minor portion of the mat $K$ gene sequence, indicating that this site has discriminated differently and is susceptible to nucleotide alterations and mutations among various species, leading to variability among species.

An estimated value of 1.16 was obtained for the $\mathrm{dN} / \mathrm{dS}$ proportion in Allium species (Table 6), suggesting the positive selection of the matK gene in Allium species in the course of evolution. This kind of evolution has led to new species and stabilized better refinement of their efficacy during the evolution, which arises from the conversion of non-coding gene sites to the gene coding sites. The same as Tajima's D and Fu's Fs, neutrality tests were obtained to determine deviations from the null theory on the neutral
Table 7 Results obtained from an evaluation of the natural evolution of the matk gene in Allium species

\begin{tabular}{ccc}
\hline Fu's Fs & Tajima's D & Gene \\
\hline-1.19 & -1.50 & matK \\
\hline
\end{tabular}

evolution and identify the impacts of natural selection on these genes in Allium species. Significantly negative estimates of D (-1.50) and Fu's Fs (-1.19) are made by groups of people under the influence of recently advanced or highly developed effective population size or the directional selection. Positively estimated values of D and Fs indicate the influences of the genetic drift, genetic dilemma, or a balancing effect over the evolutionary history of the population. The findings of the present research proved negative estimates of D and Fs (Table 7). The negative and positive results represent a significantly slight dissimilarity between polymorphisms with regard to their frequency, respectively. According to the outcomes of both neutrality tests, the continuing development of the Allium species has affected the planet or directional selection has influenced this gene throughout evolution. Altogether, Fu's Fs and Tajima's D tests have been proven to have higher effectiveness for small size and larger estimated populations.

It is of paramount importance to determine haplotype groups (by the popART software) for determination of the geographic regions of the examined breeds in comparison to other breeds. The entire 46 samples grouped in haplotype 


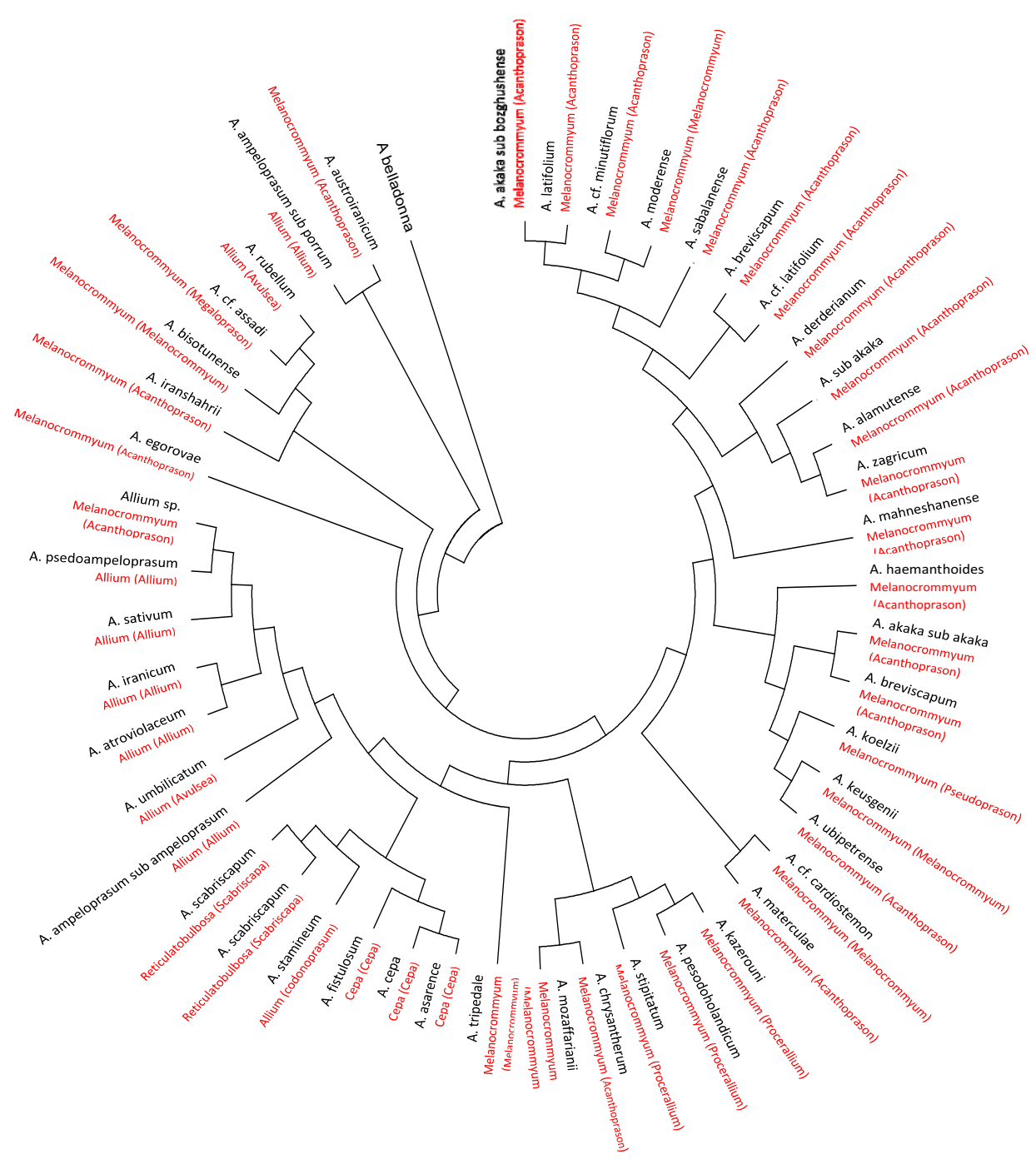

Fig. 2 Neighbor-joining phylogenetic tree analysis of 46 Allium species based on the nucleotide sequences of a matK region

bunch B is the largest in various species around the world. Based on our observations, the haplogroup A is usually present in all continents, and the haplogroup B may similarly have originated from Asia (Fig. 3) (Ghanbari et al., 2018).

The NJ tree was drawn by the Kimura distance (determination of distances aimed at building $\mathrm{NJ}$ tree using the MEGA 6.0 with the program defaults). The nucleotide sequences of the mat $K$ site presented no significantly different topology from the MP tree (MP tree was produced using the MEGA 6.0 by the program defaults), which differed in their branch-length (Kimura, 1980; Nei and Kumar, 2000).

In the current investigation, the $m a t K$ gene sequence of Amaryllis belladonna was utilized for the outside group. Phylogenetic assays that depended on the nucleotide sequences of $m a t K$ could mostly differentiate subgenera and sections in the genus Allium; though, few accessions of species were located outside of the section. Three discrete clades were produced by the NJ dendrogram. The first clade consisted of species A. austroiranicum and A. ampeloprasum. The second clade comprised the species $A$. iranshahrii, $A$. bisotunense, A. cf assadi, and A. rubellum, and the rest of species lied in the third clade.

A. egorovae presented middle sites between groups of the first and the second evolutionary lines in the tree topology. The produced mat $K$ phylogenetic tree endorsed the theory of Allium as a monophyletically originated genus. Some species analyzed phylogenetically for the mat $K$ site revealed that accessions were placed in distant clades. $A$. ampeloprasum lied in a clade near $A$. umbilicatum and another accession of $A$. ampeloprasum had a place in a distant clade with $A$. austroiranicum. The majority of the species were also distinguished by $m a t K$, and few species with close relations were not distinguishable. A. zagricum and $A$. alamutense lied in a similar clade without any distinct dissimilarities. 


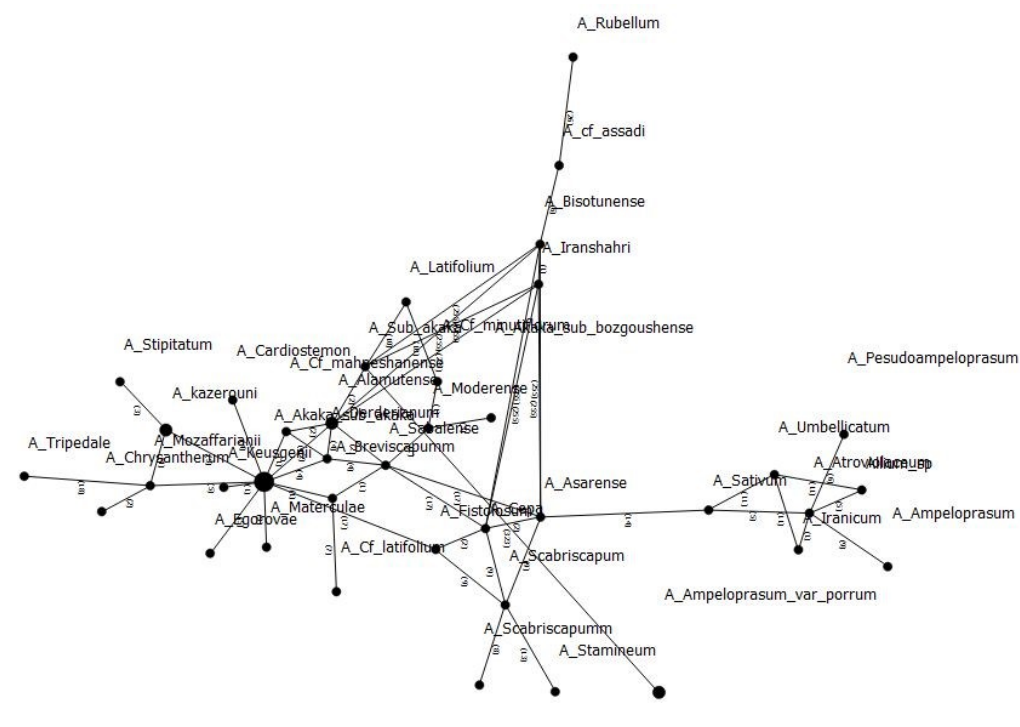

Fig. 3 Interconnectivity grid of the varieties of Allium species studied using the matK gene (popART software)

\section{Discussion}

In a previous study, the matk gene was proposed for resolving phylogenetic associations in plant species (Abugalieva et al. 2017; İpek et al. 2014 Ito et al. 1999; Kim et al. 2018; Son et al. 2010). The genes utilized for DNA barcoding in plant populations include matK, rpoCl, rpoB, trnH-PsbA, $r b c L$, atpF-atpH, $p s b K-p s b I$, and their combinations, of which, $m a t K$ and $r b c L$ were adopted as 2-locus DNA barcode by the CBOL Group (Hollingsworth et al. 2009). Polymorphic barcode nucleotide sequences are desirable at interspecific or upper classification levels, but not at the intraspecific level. Accordingly, comparison of the barcode nucleotide sequence can identify an unidentified plant accession as a species (Hebert et al. 2003; Kress and Erikson, 2008; Pang et al. 2011; Stoeckle, 2003). Additionally, the DNA fragment used as barcoding should have high recoverability, high proportion in species identification, and proper affordability (Burgess et al. 2011).

Here, the efficacy of the mat $K$ gene was examined as a DNA barcode for discriminating Allium species. Our findings indicated that $m a t K$ sites could be easily amplified by PCR. DNA sections were mostly discrete parts in Allium. Nevertheless, some species were not distinguishable from one another by the $m a t K$ sites (Abugalieva et al. 2017; Ince et al. 2005; İpek et al. 2014; Li et al. 2011; Son et al. 2010).

The length of mat $K$ nucleotide sequences varied between $540 \mathrm{bp}$ in A. porrum and A. austroiranicum and $1023 \mathrm{bp}$ in Allium sp. Genetic associations among Allium species were examined through the polymorphisms within the nucleotide sequences of trnH-psbA, ITS and matK in a recent report (İpek et al. 2014; Son et al. 2010). Over one haplotype in both organellar and nuclear genomes were present in a single plant of Allium species, making phylogeny analysis and barcoding implausible applying the nucleotide arrays of these DNA sites. At present, 39 haplotypes were noticed in Allium species for matK in the plastid genome.

Phylogenetic associations among Allium species on the basis of $m a t K$ analyses are in line with earlier research by the use of the matK site (Abugalieva et al. 2017; Gurushidze et al. 2007; İpek et al. 2014; Li et al. 2010). A. asarence and $A$. cepa lied jointly in a group with no polymorphisms in some investigations ( $\mathrm{Li}$ et al. 2010; Nguyen et al. 2008). Likewise, A. asarence and A. cepa put together in a cluster by analyzing $m a t K$ in the present research. Moreover, an accession of $A$. ampeloprasum was tightly grouped with $A$. umbilicatum and $A$. atroviolaceum, which is almost similar to those of Nguyen et al. and Hirschegger et al. On the other side, an accession of $A$. ampeloprasum (var. porrum) lied in close grouping with A. austroiranicum. A. Akaka was placed tightly in a group with $A$. breviscapum and $A$. sub akaka was assigned to a group close to A. alamutense and A. zagricum, which have a closer relation to a recently published report (Akhavan et al. 2015; Li et al. 2010; Nguyen et al. 2008). Similar to a latest investigation, A. pseudoampeloprasum was clustered tightly to $A$. atroviolaceum, $A$. iranicum, and A. sativum in our research ((Hirschegger et al. 2010; Veiskarami et al. 2019). A. umbilicatum lied in a group with $A$. ampeloprasum and $A$. atroviolaceum, which corresponds to a latest research (Friesen et al. 2006; Li et al. 2010). A. fistulosum was in group close to A. cepa and A. asarence as reported previously (Veiskarami et al. 2019; 
Li et al. 2010; Friesen et al. 2006). A similar finding was reported in an earlier study (Akhavan et al. 2015; Friesen et al. 2006; Fritsch and Abbasi, 2013; Fritsch et al. 2010; Gurushidze et al. 2010; Li et al. 2010; Sýkorová et al. 2006). Two accessions of $A$. scabriscapum were positioned in a similar clade and clustered closely with $A$. asarence, A. cepa, and $A$. fistulosum by analyzing $m a t K$, which is in agreement with a recently studied case (Friesen et al. 2006; Veiskarami et al. 2019). As detected in a recently published study, $A$. sub Akaka, A. zagricum, and A. alamutense were put together with no distance (Akhavan et al. 2015; Fritsch et al. 2010; Gurushidze et al. 2008; Li et al. 2010).

These observations indicated a close relation between Allium species in subgenera Allium and Reticulatobulbosa. Likewise, it was recently demonstrated that species in these subgenera were closely related phylogenetically (Friesen et al. 2006; Li et al. 2010). All accessions of Allium species in subgenus Allium were grouped in a similar clade. Yet, A. rubellum and A. stamineum from subgenus Allium were placed in the clade of subgenus Melanocrommyum and Reticolatobulbosa with matK examinations. This finding suggests that mixtures are present in these accessions. Accessions relating to the subgenus Melanocrommyum were put together in a clade and endorsed by a $100 \%$ bootstrap value. Similarly, the present outcomes according to the matK site revealed that these species had close phylogenetic relations. To conclude on the basis of mat $K$ examination, phylogenetic associations among Allium species scrutinized here corresponded to those reported previously ( $\mathrm{Li}$ et al. 2010; Veiskarami et al. 2019).

Here, A. mahneshanense was grouped with A. zagricum whereas it was clustered with $A$. cf. minutiflorum elsewhere. A. cf. minutiflorum was gathered with $A$. moderense while it was assigned to another Allium spp. elsewhere. In the current research, A. iranshahrii, A. bisotunense, and $A$. cf. assadi were put together tightly whereas $A$. bisotunense was clustered with $A$. keusgenii and $A$. iranshahrii was assigned closely to $A$. haemanthoides in other investigations. (Akhavan et al. 2015; Gurushidze et al. 2008; Li et al. 2010). It is proposed to utilize mat $K$ as an additional means for analyzing Allium phylogenetically as using the matK site had more simplicity for recouping and more affordability than other sites. The present information indicated that the sampled Allium species were related to the subgenera in the second and third evolutionary lines (Friesen et al. 2006; Fritsch and Abbasi 2013). The dendrogram in the mat $K$ examination recommends that species in the subgenus Melanocrommyum developed earlier than in the subgenus Allium, and these two subgenera possess a shared genetic node (Fig. 2).

As in the phylogenetic tree drawn in Friesen et al. (2006) in which subclades Polyprason, Reticulatobulbosa, and Cepa formed three sister subclades, three subclades were detected herein. The first subclade was species from the subgenera Melanocrommyum, whereas the succeeding one contained species of Allium and cepa. Our presented phylogeny of $m a t K$ suggests that five subgroups can be distinguished within subgenus Melanocrommyum. A. stipitatum, A. kozerouni, and $A$. pseudoholandicum are the representatives of the first group (section procelarium). A. chrysantherum, A. mozaffarianii, A. cf. cardiostemon, A. keusgenii, A. moderense, and A. bisotunense (section Melanocrommyum) comprise the second group, A. koelzii (section pseudoprason) belongs to the third group, A. cf. assadi (section megaloprason) is related to the fourth group, and the rest of species from section Acanthoprason form the fifth group.

A research confirmed the Allium genus originated monophyletically, which was proved in some other literature (Friesen et al. 2006; Li et al. 2010; Nguyen et al. 2008). Additionally, a thorough research compared Melanocrommyum species and mainly focused on the morphological and molecular genetic explanation of species cultivated in Iran. In spite of the fact that Fritsch and Abbasi (Fritsch and Abbasi, 2013) studied fundamentally the phylogenetic taxonomy of the Allium genus, lots of ill-known Allium taxa remain accessible in all around the country. To evaluate the phylogeny of 46 endemics, scarce Allium species with economic importance from Iran, the matK DNA barcoding marker was employed in this research.

\section{Reference}

Abdulina SA. (1999) Checklist of vascular plants of Kazakhstan. Institute of Botany and Plant Introduction, Almaty, 1-187

Abugalieva S, Volkova L, Genievskaya Y, Ivaschenko A, Kotukhov Y, Sakauova G, and Turuspekov Y. (2017) Taxonomic assessment of Allium species from Kazakhstan based on ITS and matK markers. BMC plant biology 17, 258

Akhani H. (1999) Studies on the flora and vegetation of the Golestan National Park, NE Iran*. III. Three new species, one new subspecies and fifteen new records for Iran. Edinburgh Journal of Botany 56, 1-31

Akhavan A, Saeidi H, Rahiminejad MR, Zarre S, and Blattner FR. (2015) Interspecific relationships in Allium subgenus Melanocrommyum sections Acanthoprason and Asteroprason (Amaryllidaceae) revealed using ISSR markers. Systematic botany 40(3), 706-715

Bandara NL, Papini A, Mosti S, Brown T, and Smith LMJ. (2013) A phylogenetic analysis of genus Onobrychis and its relationships 
within the tribe Hedysareae (Fabaceae). Turkish Journal of Botany 37(6), 891-992

Brochmann C, Xiang QY, Brunsfeld SJ, Soltis DE, and Soltis PS, (1998) Molecular evidence for polyploid origins in Saxifraga (Saxifragaceae): the narrow arctic endemic S. svalbardensis and its widespread allies. American Journal of Botany 85, 135-143

Burgess KS, Fazekas AJ, Kesanakurti PR, Graham SW, Husband BC, Newmaster SG, and Barrett SC. (2011). Discriminating plant species in a local temperate flora using the rbcL + matK DNA barcode. Methods in Ecology and Evolution 2(4), 333-340

Choi HJ, Giussani LM, Jang CG, Oh BU, and Cota-Sánchez JH. (2012) Systematics of disjunct northeastern Asian and northern north American Allium (Amaryllidaceae). Botany 90(6), 491-508

De Mattia F, Bruni I, Galimberti A, Cattaneo F, Casiraghi M, and Labra M. (2011) A comparative study of different DNA barcoding markers for the identification of some members of Lamiacaea. Food Research International 44(3), 693-702

Edgar RC. (2004) MUSCLE: multiple sequence alignment with high accuracy and high throughput. Nucleic acids research 32(5), 1792-1797

Friesen N, Fritsch RM, and Blattner FR. (2006) Phylogeny and new intrageneric classification of Allium (Alliaceae) based on nuclear ribosomal DNA ITS sequences. Aliso: A Journal of Systematic and Evolutionary Botany 22, 372-395

Fritsch RM, and Friesen N. (2002) Evolution, domestication and taxonomy. Allium crop science: recent advances, 5-30

Fritsch RM, Khassanov FO, and Matin F. (2002). New Allium taxa from Middle Asia and Iran. na

Fritsch RM, Salmaki Y, Zarre S, and Joharchi M. (2006) The genus Allium (Alliaceae) in Iran: current state, new taxa and new records. Rostaniha 7(2), 255-281

Fritsch RM, and Abbasi M. (2008) New taxa and other contributions to the taxonomy of Allium L. (Alliaceae) in Iran

Fritsch RM, and Abbasi M. (2013) A taxonomic review of Allium subg. Melanocrommyum in Iran. Leibniz-Institut für Pflanzengenetik und Kulturpflanzenforschung

Fritsch RM, Blattner FR, and Gurushidze M. (2010) New classification of Allium L. subg. Melanocrommyum (Webb \& Berthel.) Rouy (Alliaceae) based on molecular and morphological characters. Phyton (Horn) 49(2), 145-220

Fritsch RM, and Maroofi H. (2010) New species and new records of Allium L. (Alliaceae) from Iran. Phyton (Horn) 50, 1-26

Fritsch RM, Matin F, and Klaas M. (2001) Allium vavilovii M. Popov et Vved. and a new Iranian species are the closest among the known relatives of the common onion $A$. cepa $\mathrm{L}$. (Alliaceae). Genetic Resources and Crop Evolution 48(4), 401-408

Fuse S, and Tamura MN. (2000) A phylogenetic analysis of the plastid matK gene with emphasis on Melanthiaceae sensu lato. Plant Biology 2(4), 415-427

Ghanbari S, Fakheri BA, Naghavi MR, and Mahdinezhad N. (2018) Evaluating phylogenetic relationships in the Lilium family using the ITS marker. Journal of Plant Biotechnology 45(3), 236-241

Govaerts R, Kingto, S, Friesen N, Fritsch RM, Snijman DA, Marcucci R, Silverstone Sopkin PA. and Brullo S. (2005-2014). World checklist of Amaryllidaceae (WWW Document)

Hollingsworth PM, Forrest LL, Spouge JL, Hajibabaei M, Ratnasingham S, and Fazekas AJ. (2009) A DNA barcode for land plants. Proceedings of the National Academy of Sciences 106(31), 12794-12797

Guo J, SU JX, LIN RZ, LI RQ, and XIAO PG. (2011) Testing four proposed barcoding markers for the identification of species within Ligustrum L. (Oleaceae). Journal of Systematics and Evolution 49(3), 213-224

Guo X, Simmons MP, BUT PPH, SHAW PC, and WANG RJ. (2011) Application of DNA barcodes in Hedyotis L. (Spermacoceae, Rubiaceae). Journal of Systematics and Evolution 49(3), 203-212

Gurushidze M, Fritsch RM, and Blattner FR. (2010) Species-level phylogeny of Allium subgenus Melanocrommyum: Incomplete lineage sorting, hybridization and trnF gene duplication. Taxon 59(3), 829-840

Gurushidze M, Mashayekhi S, Blattner FR, Friesen N, and Fritsch RM. (2007) Phylogenetic relationships of wild and cultivated species of Allium section Cepa inferred by nuclear rDNA ITS sequence analysis. Plant Systematics and Evolution 269(3-4), 59-269.

Hall TA. (1999). BioEdit: a user-friendly biological sequence alignment editor and analysis program for Windows 95/98/NT. In Nucleic acids symposium series 41, 95-98

Harpke D, Meng S, Rutten T, Kerndorff H, and Blattner FR. (2013) Phylogeny of Crocus (Iridaceae) based on one chloroplast and two nuclear loci: ancient hybridization and chromosome number evolution. Molecular phylogenetics and evolution 66(3), 617-627

Hebert PD, Cywinska A, Ball SL, and Dewaard JR. (2003) Biological identifications through DNA barcodes. Proceedings of the Royal Society of London. Series B: Biological Sciences, 270(1512), 313-321

Hirschegger P, Jakše J, Trontelj P, and Bohanec B. (2010) Origins of Allium ampeloprasum horticultural groups and a molecular phylogeny of the section Allium (Allium: Alliaceae). Molecular Phylogenetics and Evolution 54(2), 488-497

Huang X, and Madan A. (1999) CAP3: A DNA sequence assembly program. Genome research, 9(9), 868-877

Ipek M, İpek A, and Simon PW. (2014) Testing the utility of matK and ITS DNA regions for discrimination of Allium species. Turkish journal of botany, 38(2), 203-212

Ito M, Kawamoto A, Kita Y, Yukawa T, and Kurita S. (1999) Phylogenetic relationships of Amaryllidaceae based on matK sequence data. Journal of Plant Research 112(2), 207-216

Jing YU, Jian-Hua XUE, and Shi-Liang ZHOU. 2011. New universal matK primers for DNA barcoding angiosperms. Journal of Systematics and Evolution, 49(3), 176-181

Ince AG, Karaca M, Onus AN, and Bilgen M. (2005) Chloroplast matK gene phylogeny of some important species of plants. 
Akdeniz Universites Iziraatfakultesi Dergisi 18, 157-162

Kamelin R, and Seisums A. (1996) "Tri novykh vida roda Allium L." Alliaceae) iz yugo-zapadnoi Azii. (Tres species novae generis Allium L. (Alliaceae) ex Asia austro-occidentali.) Novosti Sistematiki Vysshikh Rastenii 30, 29-33

Khassanov FO, and Memariani F. (2006) Allium joharchii, a new species from Khorasan Province (Iran). Rostaniha 7(2), 63-69

Khassanov FO, Noroozi J, and Akhani H. (2006) Two new species of the genus Allium (Alliaceae) from Iran. Rostaniha 7(2), 119-129

Kim YB, Ramekar RV, Choi SJ, Choi BG, Kim SW, Moon YK, and Choi IY. (2018) Molecular identification of Allium ochotense and Allium microdictyon using multiplex-PCR based on single nucleotide polymorphisms. Horticulture, Environment, and Biotechnology 59(6), 865-873

Kimura M. (1980) A simple method for estimating evolutionary rates of base substitutions through comparative studies of nucleotide sequences. Journal of molecular evolution 16(2), 111-120

Koch M, Haubold B, and Mitchell-Olds T. (2001) Molecular systematics of the Brassicaceae: evidence from coding plastidic matK and nuclear Chs sequences. American Journal of Botany 88(3), 534-544

Kress WJ. (2017) Plant DNA barcodes: Applications today and in the future. Journal of systematics and evolution 55(4), 291-307

Kress WJ, and Erickson DL. (2008) DNA barcodes: genes, genomics, and bioinformatics. Proceedings of the National Academy of Sciences 105(8), 2761-2762

Lahaye R, Van der Bank M, Bogarin D, Warner J, Pupulin F, Gigot G, and Savolainen V. (2008) DNA barcoding the floras of biodiversity hotspots. Proceedings of the National Academy of Sciences 105(8), 2923-2928

Leigh JW, and Bryant D. (2015) popart: full-feature software for haplotype network construction. Methods in Ecology and Evolution 6(9), 1110-1116

Li FW, Kuo LY, Rothfels CJ, Ebihara A, Chiou WL, Windham MD, and Pryer KM. (2011) rbcL and matK earn two thumbs up as the core DNA barcode for ferns. PLoS One 6(10), e26597

Li QQ, Zhou SD, He XJ, Yu Y, Zhang YC, and Wei XQ. (2010) Phylogeny and biogeography of Allium (Amaryllidaceae: Allieae) based on nuclear ribosomal internal transcribed spacer and chloroplast rps 16 sequences, focusing on the inclusion of species endemic to China. Annals of botany 106(5), 709-733

Li X, Yang Y, Henry RJ, Rossetto M, Wang Y, and Chen S. (2015) Plant DNA barcoding: from gene to genome. Biological Reviews 90(1), 157-166

Mashayekhi S, Zarre S, Fritsch RM, and Attar F. (2005) A new species of Allium subgen. Melanocrommyum sect. Compactoprason (Alliaceae) from Iran. Feddes Repertorium: Zeitschrift für botanische Taxonomie und Geobotanik 116(3-4), 191-194

Matin F. (1992) The genus Allium in Iran, diversity, distribution and endemism. In The genus Allium-taxonomic problems and genetic resources. Proceedings of an international symposium held at Gatersleben 193-194

Memariani F, Joharchi MR, and Arjmandi AA. (2012) Allium aladaghense (Amaryllidaceae, Allieae), a new species of section Asteroprason from northeast of Iran. Phytotaxa 56(1), 28-34

Memariani F, Jouharchi M, and Khassanov FO. (2007) Allium L. subgen. Rhizirideum sensu lato in Iran, two new records and a synopsis of taxonomy and phytogeography

Nei M, and Kumar S. (2000) Molecular evolution and phylogenetics. Oxford university press

Neshati F, Zarre S, Fritsch RM, and Joharchi MR. (2009) Allium oriento-iranicum (Alliaceae), a new species from Iran. In Annales Botanici Fennici 46(6), 599-602

Nguyen NH, Driscoll HE, and Specht CD. (2008) A molecular phylogeny of the wild onions (Allium; Alliaceae) with a focus on the western North American center of diversity. Molecular Phylogenetics and Evolution 47(3), 1157-1172

Pang X, Song J, Zhu Y, Xu H, Huang L, and Chen S. (2011) Applying plant DNA barcodes for Rosaceae species identification. Cladistics 27(2), 165-170

Picoult-Newberg L, Ideker TE, Pohl MG, Taylor SL, Donaldson MA, Nickerson DA, and Boyce-Jacino M. (1999) Mining SNPs from EST databases. Genome Research (9), 167-174

Razyfard H, Zarre S, Fritsch RM, and Maroofi H. (2011) Four new species of Allium (Alliaceae) from Iran. In Annales Botanici Fennici 48(4), 352-361

Seberg O, Petersen G, Davis JI, Pires JC, Stevenson DW, Chase MW, and Pillon Y. (2012) Phylogeny of the Asparagales based on three plastid and two mitochondrial genes. American Journal of Botany 99(5), 875-889

Son JH, Park KC, Kim TW, Park YJ, Kang JH, and Kim NS. (2010) Sequence diversification of $45 \mathrm{~S}$ rRNA ITS, trnH-psbA spacer, and matK genic regions in several Allium species. Genes \& Genomics 32(2), 165-172

Steele KP, and Vilgalys R. (1994) Phylogenetic analyses of Polemoniaceae using nucleotide sequences of the plastid gene matK. Systematic Botany 126-142

Stoeckle M. (2003) Taxonomy, DNA, and the bar code of life. BioScience 53(9), 796-797

Sýkorová E, Fajkus J, Mezníková M, Lim KY, Neplechová K, Blattner FR, and Leitch AR. (2006) Minisatellite telomeres occur in the family Alliaceae but are lost in Allium. American journal of botany $93(6), 814-823$

Tamura K, Peterson D, Peterson N, Stecher G, Nei M, and Kumar S. (2011) MEGA5: molecular evolutionary genetics analysis using maximum likelihood, evolutionary distance, and maximum parsimony methods. Molecular biology and evolution 28(10), 2731-2739

Tamura MN, Yamashita J, Fuse S, and Haraguchi M. (2004) Molecular phylogeny of monocotyledons inferred from combined analysis of plastid matK and $r b c L$ gene sequences. Journal of Plant Research 117(2), 109-120

Tripathi AM, Tyagi A, Kumar A, Singh A, Singh S, Chaudhary LB, and Roy S. (2013) The internal transcribed spacer (ITS) region and $t r n h H-p s b A$ are suitable candidate loci for DNA 
barcoding of tropical tree species of India. PloS one 8(2), e57934

Veiskarami GH, Khodayari H, Heubl G, Weigend M, and Zarre S. (2019) Phylogenetic relationships in Allium sect. Allium (Amaryllidaceae, Allioideae) in Iran as inferred from nrDNA ITS, cpDNA rps16 and trnL-F sequences. Nordic Journal of Botany

von Berg GL, Samoylov A, Klaas M, and Hanelt P. (1996) Chloroplast DNA restriction analysis and the infrageneric grouping of Allium (Alliaceae). Plant systematics and evolution, 200(3-4), 253-261

Wendelbo P. (1971) Some distributional patterns within the Flora Iranica area. Plant Life of South West Asia

Zhi-Yuan DU, Qimike A, Chun-Feng Y, Jin-Ming C, and QingFeng W. (2011) Testing four barcoding markers for species identification of Potamogetonaceae. Journal of Systematics and Evolution 49(3), 246-251 